Safitri, R. · T. Rahayu $\cdot$ L. Widiastuti

\title{
Pengaruh macam media tanam dan konsentrasi zat pengatur tumbuh terhadap pertumbuhan stek dua nodus melati
}

Sari. Hormon auksin, giberelin, sitokinin, dan asam traumalin, serta media tanam yang tepat diketahui dapat meningkatkan pertumbuhan tunas dan akar pada stek. Penelitian ini bertujuan untuk mengetahui pengaruh konsentrasi zat pengatur tumbuh dan macam media tanam terhadap pertumbuhan stek melati (Jasminum sambac L.) dengan dua nodus. Percobaan menggunakan Rancangan Acak Lengkap (RAL) pola faktorial. Perlakuan terdiridari duafaktor dan tiga kali ulangan. Faktor yang pertama yaitu konsentrasi dari campuran zat pengatur tumbuh, terdiri dari taraf $0 ; 0,15$; dan $0,30 \mathrm{~mL} / \mathrm{L}$. Faktor kedua yaitu campuran media tanam dengan perbandingan sama, terdiri dari taraftanah dan pupuk kandang; tanah dan cocopeat; serta tanah, pupuk kandang, dan cocopeat. Analisis data menggunakan ujiJarak Berganda Duncan pada taraf nyata 5\%. Hasil percobaan menunjukkan bahwa tidak terdapat pengaruh interaksi antara konsentrasi zat pengatur tumbuh dengan macam media tanam terhadap pertumbuhan stek dua nodus melati. Pengaruh konsentrasi zat pengatur tumbuh $0,30 \mathrm{~mL} / \mathrm{L}$ secara mandiri memberikan pertumbuhan paling baik pada kecepatan tumbuh dan tinggi tunas stek. Pengaruh media tanam tanah dan pupuk kandang secara mandiri memberikan pertumbuhan paling baik pada kecepatan tumbuh dan tinggi tunas.

Kata kunci: Dua nodus $\cdot$ Media tanam $\cdot$ Melati $\cdot$ Stek $\cdot$ Zat pengatur tumbuh

\section{The effectof planting media andplant growth regulator concentrationon the growth of two nodes cutting of jasmine}

\begin{abstract}
The plant hormones such as auxin, gibberellin, cytokinins, and traumalic acid, as well as appropriate growing media, are known to increase shoot and root growth on cuttings. This study aims to determine the effect of the concentration of plant growth regulators and the growing media on the growth of two nodesjasmine (Jasminum sambac L.) cuttings. The experiment used a factorial completely randomized design. The treatment consisted of two factors and three replications. The first factor was the concentration of a mixture of plant growth regulators, consisted of levels: $0 ; 0.15$; and $0.30 \mathrm{~mL} / \mathrm{L}$. The second factor was mixture of growing media with the same ratio, consisted of levels: soil and manure; soil and cocopeat; and soil, manure, and cocopeat. Data analysis used the Duncan Multiple Range test at the $5 \%$ significant level. The results showed that there was no interaction effect between the concentration of growth regulators and the growing media on the growth of two nodes of jasmine cuttings. The single effect of concentration of plant growth regulator $0.30 \mathrm{~mL} / \mathrm{L}$ gave the best growth at the growth rate and shoot height. The single effect of soil and manure gave the best growth at growth rate and shoot height.
\end{abstract}

Keywords: Cuttings · Jasmine $\cdot$ Growing media $\cdot$ Growth regulators · Two nodes

Diterima : 12 September 2020, Disetujui : 14 April 2021, Dipublikasikan : 16 April 2021

doi: https://doi.org/10.24198/kultivasi.v20i1.29419

Safitri, R. · T. Rahayu $\cdot$ L. Widiastuti

Prodi Agroteknologi Universitas Islam Batik Surakarta

Korespondensi: airakiranahebat@gmail.com 


\section{Pendahuluan}

Tanaman melati (Jasminum sambac) merupakan salah satu tanaman bunga hias yang telah banyak dikenal masyarakat Indonesia yang berasal dari berbagai daerah di Asia, Afrika, dan Australia. Bunga melati juga dapat digunakan sebagai pewangi teh, penghias pengantin, kosmetik, obat tradisional dan bahan parfum, sementara akar, batang dan daunnya dapat digunakan sebagai obat tradisional (Khair et al., 2013).

Perbanyakan tanaman melati pada umumnya dilakukan secara vegetatif (batang). Perbanyakan dengan cara ini lebih menguntungkan dibandingkan dengan cara okulasi, cangkok, maupun rundukan, hal ini dikarenakan tidak memerlukan keahlian khusus, memberikan sifat seperti induknya dan menghasilkan tanaman yang seragam dalam jumlah banyak (Muslimah et. al., 2019). Perbanyakan melati dapat menggunakan stek dengan satu atau dua nodus (Wuryaningsih dan Andyantoro, 1998). Stek dua nodus lazim digunakan oleh petani karena persentase keberhasilannya lebih besar (Handayani, 2006).

Kendala yang dihadapi dalam stekbatang adalah lambatnya pembentukan akar, tunas,dan pertumbuhannya tidak normal.Masalah tersebut dapat diatasi diantaranyadengan pemberian zat pengatur tumbuh (ZPT). Zat pengatur tumbuh adalah senyawa organik bukan hara yang dalam jumlah tertentu dapat mendukung, menghambat, dan mengubah proses fisiologi tanaman. Peranan penting ZPT adalah pada pembelahan dan diferensiasi sel. Zat pengatur tumbuh dapat merangsang pertumbuhan akar, dan memperpanjang sel tanaman, sehingga mampu mengurangi angka kegagalan dalam penyetekan (Wulandariet al., 2013).Auksin mempercepat keluarnya akar-akar baru (Malfirani et al., 2014). Giberelin dapat memacu pertumbuhan daun, pemanjangan akar, serta munculnya tunas, sementara sitokinin dapat meningkatkan pertumbuhan tunas (Tambunan et al., 2018). Asam traumalin dapat mempercepat penutupan luka pada stek (Salisbury dan Ross, 1995).

Menurut Ashari (2006) media tanam merupakan faktor yang perlu diperhatikan, dalam menanam stek agar tidak mudah goyah, memberikan kelembaban yang cukup dan mengatur aerasi. Oleh karena itu, media yang digunakan haruslah mampu memberikan aerasi yang cukup, mempunyai daya pegang air dan drainase yang baik serta bebas dari jamur dan bakteri patogen (Harjadi, 1996).

Penelitian mengenai ZPT yang mengandung auksin, giberelin, sitokinin, dan asam traumalin dengan media tanam yang tepat diharapkan dapat meningkatkan pembentukan akar dan tunas. Hal ini akan meningkatkan persentase bibit melati yang normal.

\section{Bahan dan Metode}

Penelitian ini dilaksanakan di dalam greenhouse dan disemai dalam polibeg. Tempat penelitian bertempat di kebun petani di Desa Jrangkah, RT 1/ RW 4, Sudimoro, Teras, Boyolali, Jawa Tengah, pada ketinggian tempat 265 meter di atas permukaan laut. Bahan penelitian meliputi: bibit stek melati (2 nodus); zat pengatur tumbuh yang mengandung auksin (100,55 ppm), sitokinin (90,33 ppm), gibereline (118,5 ppm), etilen (170 ppm), asam traumalin (213 ppm); tanah; pupuk kandang ayam; cocopeat; dan insektisida. Alat yang digunakan meliputi: cetok, gunting stek, meteran, gelas ukur volume $100 \mathrm{~mL}$, alat tulis, paranet 90\%, bambu, gunting, cangkul, timbangan digital, hand sprayer, dan polibeg $10 \times 20 \mathrm{~cm}$

Penelitian ini menggunakan Rancangan Acak Lengkap (RAL) faktorial. Perlakuan terdiri dari dua faktor dan tiga kali ulangan. Faktor yang pertama yaitu konsentrasi dari campuran zat pengatur tumbuh, terdiri dari taraf $0\left(\mathrm{z}_{0}\right)$; $0,15\left(z_{1}\right)$; dan $0,30\left(z_{3}\right) \mathrm{mL} / \mathrm{L}$. Faktor kedua yaitu campuran media tanam dengan perbandingan sama, terdiri dari taraf tanah dan pupuk kandang $\left(\mathrm{p}_{1}\right)$; tanah dan cocopeat $\left(\mathrm{p}_{2}\right)$; serta tanah, pupuk kandang dan cocopeat $\left(\mathrm{p}_{3}\right)$.

Parameteryang diukur pada penelitian adalah umur stek bertunas (berapa hari setelah tanam), panjang tunas (mengukur panjang tunas mulai dari pangkal tunas sampai ujung tunas), jumlah tunas (menghitung jumlah tunas yang tumbuh), volume akar (diamati dengan cara mengukur selisih volume air setelah akar dimasukan ke dalam gelas ukur), dan panjang akar (mengukur panjang dari leher sampai ujung akar). Analisis data dilakukan dengan uji DMRT pada taraf nyata $5 \%$. 


\section{Hasil dan Pembahasan}

Tidak terdapat pengaruh interaksi antara konsentrasi zat pengatur tumbuh dengan campuran macam media terhadap semua parameter pengamatan, yaitu umur tumbuh tunas, panjang tunas, jumlah tunas, volume akar, dan panjang akarstek tanaman melati.Hal ini berarti hanya terdapat pengaruh mandiri dari masing-masing faktor.

Pengaruh mandiri zat pengatur tumbuh memberikan pengaruh yang nyata terhadap parameter pengamatan umur tumbuh tunas dan panjang tunas. Konsentrasi ZPT 0,30 mL/L memberikan pengaruh paling baik terhadap umur tumbuh tunas dan panjang tunas. Meskipun tidak berbeda nyata, namun konsentrasi ZPT 0,30 mL/L cenderung meningkatkan jumlah tunas, volume akar, dan panjang akar. Pengaruh mandiri macam campuran media tanam memberikan pengaruh yang nyata terhadap umur tumbuh tunas dan panjang tunas. Pengaruh terbaik macam campuran media tanam tidak konsisten pada parameter pengamatan. Umur tumbuh tunas paling cepat dihasilkan oleh campuran tanah dengan pupuk kandang, sementara panjang tunas dihasilkan oleh campuran tanah dengan cocopeat.
Meskipun tidak berbeda nyata, namun campuran tanah dan pupuk kandang cenderung meningkatkan jumlah tunas, volume akar, dan panjang akar. (Tabel 1).

Adanya pengaruh mandiri ZPT yang dapat meningkatkan pertumbuhan tunas dan akar stek disebabkan campuran auksin, giberelin, sitokinin, dan asam traumalin yang dapat meningkatkan pertumbuhan stek. Auksin dapat memacu kerja sitokinin dalam menginduksi enzim-enzim yang berfungsi dalam pembelahan sel terutama pada primordia daun (Salisbury dan Ross, 1995). Pemberian auksin memacu pemanjangan potongan akar atau bahkan akar utuh pada banyak spesies, tapi hanya pada konsentrasi yang sangat rendah. Selain itu, auksin juga memacu perkembangan akar liar pada batang. Penelitian ini sejalan dengan penelitian Yunanda et al.(2015), yang menyatakan bahwa pemberian auksin dengan konsentrasi $50 \%$ memberikan pengaruh nyata terhadap volume akar, hal ini disebabkan auksin yang dibutuhkan untuk pemanjangan akar dan jumlah akar memiliki respon relatif lebih baik pada konsentrasi $50 \%$ peranzat pengatur tumbuh auksin ini dapat optimal dalam mengaktifkan enzim-enzim yang berperan dalam pembuatan komponen sel auksin akan merangsang pembentukan sel-sel dengan cepat (Winten, 2009).

Tabel 1. Pengaruh ZPT dan macam media tanam terhadap pertumbuhan stek dua nodus melati.

\begin{tabular}{|c|c|c|c|c|c|}
\hline \multirow{2}{*}{ Parameter } & \multirow{2}{*}{$\begin{array}{c}\text { Campuran macam } \\
\text { media tanam }\end{array}$} & \multicolumn{3}{|c|}{ Konsentrasi zat pengatur tumbuh } & \multirow[t]{2}{*}{ Rerata } \\
\hline & & $\mathrm{Z}_{0}$ & $\mathrm{Z}_{1}$ & $\mathrm{Z}_{2}$ & \\
\hline \multirow{4}{*}{$\begin{array}{l}\text { 1. Umur tumbuh } \\
\text { tunas (hari) }\end{array}$} & $\mathrm{p}_{1}$ & 25,67 & 25,41 & 19,74 & $23,60 a$ \\
\hline & $\mathrm{p}_{2}$ & 26,55 & 25,52 & 23,47 & $24,75 c$ \\
\hline & $\mathrm{p}_{3}$ & 26,89 & 24,23 & 22,40 & $24,50 \mathrm{~b}$ \\
\hline & Rerata & $26,37 \mathrm{c}$ & $25,06 b$ & $21,87 a$ & \\
\hline \multirow{4}{*}{$\begin{array}{l}\text { 2. Jumlah tunas } \\
\text { (buah) }\end{array}$} & $\mathrm{p}_{1}$ & 1,40 & 1,84 & 2,11 & 1,78 \\
\hline & $\mathrm{p}_{2}$ & 1,41 & 1,86 & 1,96 & 1,74 \\
\hline & $\mathrm{p}_{3}$ & 1,25 & 1,83 & 2,00 & 1,69 \\
\hline & Rerata & 1,35 & 1,84 & 2,02 & \\
\hline \multirow{4}{*}{$\begin{array}{l}\text { 3. Panjang tunas } \\
\qquad(\mathrm{cm})\end{array}$} & $\mathrm{p}_{1}$ & 0,27 & 0,25 & 0,43 & $0,32 c$ \\
\hline & $\mathrm{p}_{2}$ & 0,24 & 0,31 & 0,39 & $0,30 b$ \\
\hline & $\mathrm{p}_{3}$ & 0,22 & 0,29 & 0,37 & $0,29 a$ \\
\hline & Rerata & $0,24 a$ & $0,28 b$ & $0,40 \mathrm{c}$ & \\
\hline \multirow{4}{*}{$\begin{array}{l}\text { 4. Volume akar } \\
\qquad(\mathrm{mL})\end{array}$} & $\mathrm{p}_{1}$ & 0,51 & 1,18 & 1,71 & 1,13 \\
\hline & $\mathrm{p}_{2}$ & 0,27 & 0,78 & 1,15 & 0,73 \\
\hline & $\mathrm{p}_{3}$ & 0,40 & 0,91 & 0,91 & 0,74 \\
\hline & Rerata & 0,39 & 0,96 & 1,26 & \\
\hline \multirow{4}{*}{ 5. Panjang akar (cm) } & $\mathrm{p}_{1}$ & 4,95 & 7,93 & 10,87 & 7,91 \\
\hline & $\mathrm{p}_{2}$ & 4,67 & 6,91 & 8,83 & 6,80 \\
\hline & $\mathrm{p}_{3}$ & 4,55 & 7,77 & 9,08 & 7,13 \\
\hline & Rerata & 4,72 & 7,54 & 9,59 & \\
\hline
\end{tabular}

Keterangan: Rerata yang diikuti huruf yang berbedapada baris atau kolom yang samamenunjukkan berbeda nyata berdasarkanuji Duncan pada taraf nyata $5 \%$. 
Proses penutupan luka pada stek dibantu oleh asam traumalin sehingga stek pada perlakuan ZPT lebih cepat tumbuh (Salisbury dan Ross, 1995). Setelah tumbuh, giberelin meningkatkan pertumbuhan stek tersebut. Giberelin terbukti dapat meningkatkan pemanjangan batang dan peningkatan jumlah sel pada bibit melati (Yulia et al., 2012; Tambunan et al., 2018).

Kandungan sitokinin dalam zpt mampu memacu pembelahan sel pada primordia daun yang mendukung bertambahnya jumlah daun. Sitokinin mampu mempercepat pembentukan daun dan memacu pembelahan serta pembesaran sel. Auksin dapat memacu kerja sitokinin dalam proses pembelahan dan pembesaran sel (Salisbury dan Ross, 1995; Tambunan et al., 2018).

Waktu pertumbuhan stek paling cepat pada perlakuan $Z_{2}$ (yang berbeda nyata dengan perlakuan $Z_{1} /$ konsentrasi zat pengatur tumbuh 0,15 ml/1 dan $Z_{0} /$ konsentrasi zat pengatur tumbuh $0 \mathrm{ml} / \mathrm{l})$. Hal ini diduga pada konsentrasi zat pengatur tumbuh $0,30 \mathrm{ml} / 1$ yang digunakan pada stek melati terjadi keseimbangan dan interaksi dari zat pengatur tumbuh endogen dan eksogen, sehingga mampu merangsang proses fisiologis dalam pertumbuhan dan perkembangan tanaman terutama pada bagian-bagian vegetaif dari tanaman (Siskawatiet al., 2013).

Berdasarkan dari hasil penelitian Huik (2004), menunjukan bahwa zat pengatur tumbuh berpengaruh nyata terhadap persentase tumbuh tunas, jumlah akar, berat kering akar, berat kering tunas, dan mengindikasikan bahwa pemberian zat pengatur tumbuh dapat menunjukkan pertumbuhan dan perkembangan stek batang.

Uji lanjut dengan DMRT pada parameter tinggi tunas diperoleh waktu pertumbuhan stek paling cepat pada perlakuan $Z_{2}$ (yang berbeda nyata dengan perlakuan $Z_{1} /$ konsentrasi zat pengatur tumbuh0,15 $\mathrm{ml} / 1$ dan $\mathrm{Z}_{0} /$ konsentrasi ZPT $0 \mathrm{ml} / \mathrm{l})$. Hal ini diduga karena zat pengatur tumbuh mengandung bahan aktif NAA, NAD dan IBA sebagai sumber auksin yang memiliki keefektifan khusus dalam merangsang pertumbuhan akar.

Campuran macam media tertinggi ditunjukkan pada taraf $\mathrm{P}_{1}$ (tanah dan pupuk kandang) karena komposisi kedua media ini kaya akan nutrisi dan unsur hara, dan sifatnya lebih porous sehingga media tidak terlalu lembab dan baik untuk pertumbuhan stek (Ashari, 2006). Pupuk kandang yang telah matang tidak akan menimbulkan gangguan pada stek, bahkan meningkatkan pertumbuhan stek (Firdiana et al., 2019; Ichwan et al., 2020).

\section{Kesimpulan}

Hasil penelitian menunjukkan bahwa:

1. Tidak terdapat pengaruh interaksi antara konsentrasi zat pengatur tumbuh dengan macam media tanam terhadap pertumbuhan stek dua nodus melati

2. Penggunaan konsentrasi ZPT 0,30 mL/L secara mandiri memberikan pengaruh yang paling baik pada kecepatan tumbuh dan tinggi tunas stek.

3. Media tanam tanah dan pupuk kandang secara mandiri memberikan pengaruh yang paling baik pada kecepatan tumbuh dan tinggi tunas.

\section{Ucapan Terima Kasih}

Penulis mengucapkan terimakasih atas bantuan selama penelitian kepada:

1. Civitas akademika Fakultas Pertanian Universitas Islam Batik Surakarta

2. Kepala Desa Sudimoro Teras Boyolali

\section{Daftar Pustaka}

Ashari, S. 2006. Hortikultura aspek budidaya. UI-Press. Jakarta.

Firdiana, E.R, dan E. Renjana. 2019. Pertumbuhan vegetatif stek daun hoya pada tiga media tanam yang berbeda. Prosiding Seminar Nasional Hayati VII.1-7.

Handayani, T. 2006. Pembibitan secara stek-mini tanaman melati (Jasminum sambac (L.)Aiton). Jurnal Sains dan Teknologi Indonesia, 8(1): 21-25.

Harjadi, S. S. 1996. Pengantar agronomi. PT. Gramedia Pustaka Utama. Jakarta.

Huik, E. M. 2004. Pengaruh rootone F dan ukuran diameter stek terhadap pertumbuhan dari stek batang jati (Tectonia grandis L. F).Jurnal sains dan teknologi Indonesia. 5 (5) : 55-63. 
Ichwan, A. Syakur, S. A. Lasmini. 2020. Pengaruh pemberian berbagai macam pupuk kandang terhadap pertumbuhan stek tanaman anggur (Vitis vinifera L.). Agrotekbis, 8(3): 588 - 596.

Khair, H., Meizal, dan Z. R. Hamdani. 2013. Pengaruh konsentrasi ekstrak bawang merah dan air kelapa terhadap pertumbuhan stek tanaman melati putih (Jasminum sambac L. ). Jurnal Agrium. 18 (2).

Malfirani, M., Y.S. Rahayu, dan E. Ratnasari. 2014. Pengaruh Pemberian Berbagai Konsentrasi Filtrat Umbi Bawang Merah dan Rootone-F terhadap Pertumbuhan Stek Melati “Rato Ebu”. LenteraBio, 3(1): 73 - 76.

Muslimah,Y, S. F. Lizmah, dan, N, Fayanti. 2019. Growth response of melati plant (Jasminum sambac L.) against types of media plants and types of growing agents. Birex Journal. 2(2):188-200.

Salisbury, F. B. dan C. W. Ross. 1995. Fisiologi tumbuhan jilid 3. Institut Teknologi Bandung. Bandung.

Siskawati, E., R. Linda, dan Mukarlina. 2013. Pertumbuhan stek batang jarak pagar (Jatropha curcas L). dengan perendaman larutan bawang merah (Allium cepaL), dan IBA (Indol Butyric Acid). Jurnal Protobiont. (2) $3: 167-170$.
Tambunan, S. B. R., N. S. Sebayang, dan W. A. Pratama. 2018. Keberhasilan pertumbuhan stek jambu madu (Syzygium equaeum) dengan pemberian zat pengatur tumbuh kimiawi dan zat pengatur tumbuh alami bawang merah (Allium cepa L.). Jurnal Biotik, 6(1): 45 - 52 .

Winten, I. T. K. 2009. Zat pengatur tumbuh dan peranannya dalam budidaya tanaman. Majalah ilmiah fakultas Pertanian. Universitas Tabanan, 6 : 49-58.

Wulandari, R. C., Riza, L., dan Mukarlina. 2013. Pertumbuhan stek melati putih (Jasminum ambac (L) W. Ait.) dengan pemberian air kelapa dan IBA (Indole Butyric Acid). Jurnal Protobiont. 2 (2): 39 -43.

Wuryaningsih, S. dan S. Andyantoro. 1998. Pertumbuhan Setek Melati Berbuku Satu Dan Dua Pada Beberapa Macam Media. Agrijurna. Vol 5: 32 - 42.

Yulia, E. N. S., L. S. Budipramana, dan E. Ratnasari. 2012. Induksi dan Pertumbuhan Kalus Batang Melati (Jasminum sambac) pada Media MS dengan Penambahan Giberelin. LenteraBio, 1(1): 49 - 53.

Yunanda, J., Murniati, dan S. Yosefa. 2015. Pertumbuhan stek batang tanaman buah naga (Hylocereus costaricensis) dengan pemberian beberapa konsentrasi urin sapi. JOM Faperta, 2(1): 1 - 8 . 